\title{
IMPLEMENTASI KEBIJAKAN PERATURAN DAERAH NOMOR 15 TAHUN 2011 TENTANG PAJAK RESTORAN OLEH BADAN PENGELOLA PAJAK DAN RETRIBUSI DAERAH KABUPATEN HULU SUNGAI UTARA
}

\author{
Sugianor \\ Sekolah Tinggi Ilmu Administrasi Amuntai \\ Email: jatiagung7@gmail.com
}

\begin{abstract}
This research is aimed at the Office of Tax Management Board And Retribution of Hulu Sungai Utara Regency which is aimed to find out how the Implementation of Regional Regulation Policy Number 15 Year 2011 on Restaurant Taxes and any Factors that participate in implementing it. The research method used is descriptive-qualitative method, data completion process by observation, interview and documentation. With a robust sample of 12 people and data analysis techniques by means of data reduction, data presentation and withdrawal. The results of research conducted on the things that have been good by the relevant agencies, will other implementers who are not helped by not participating to achieve success by paying with premises on time and follow the procedures of the direction of a solid institution then it is appropriate as said successfully touched. However, the factors that are developing are: Standards and Policy Objectives that are still not in accordance with the region, Characteristics of Implementing Agencies not yet firm and Social and Political Condition not yet understand the society. Has not understood the people who are still unclear about this tax retribution system but the role of the agency and the government is to date still leads by providing information regularly about this restaurant tax even though it has been repeatedly described so that the restaurant can understand and understand to Pay the dues. More assertiveness by the agencies in the implementation of this regulation is needed so that the public can understand clearly and avoid the prevailing provisions, and apply the applicable judicial standards.
\end{abstract}

Keywords: policy implementation, tax, restourant

\section{PENDAHULUAN}

Salah satu sumber penerimaan daerah diantaranya adalah dari sektor pajak. Secara umum pajak merupakan komponen penerimaan negara yang paling besar dan sangat memerlukan terutama dalam membiayai pembangunan. Hal ini dikarenakan pajak dapat dikenakan dan bahkan dipaksakan kepada semua warga negara yang telah memenuhi ketentuan yang berlaku sesuai dengan undang-undang. Sedangkan bagi daerah, pajak merupakan bukti nyata peran aktif masyarakat dalam membiayai roda pemerintahan dan pembangunan daerahnya. Pemungutan ini juga harus dipahami masyarakat sebagai sumber penerimaan yang dibutuhkan oleh daerah untuk meningkatkan kesejahteraan masyarakat di daerah.
Sumber daya yang mempengaruhi pendapatan asli daerah di Kabuptaen Hulu Sungai Utara sangat beraneka ragam salah satu nya dari segi retribusi pajak tersebut dimana menjadi peringkat tebesar ketiga peran nya dalam sumbangsih pembangunan ekonomi daerah pada tahun 2015. Retribusi pajak yang tinggi juga antara lain berasal dari Pajak Restoran, seperti yang tercantum pada Peraturan Daerah Kabupaten Hulu Sungai Utara Nomor 15 Tahun 2011 Tentang Pajak Restoran. Dimana terdapat yang berlokasi di kabupaten Hulu Sungai Utara, dimana pada Tahun 2014 Realisasi Anggaran Pajak Restoran senilai Rp. 801.028.567 dan mengalami peningkatan pada Tahun 2015 dengan Realisasi Anggaran Rp. 1.082.788.215 sehingga pengelolaan nya sangat 
benar benar dijalankan sesuai dengan peraturan yang ada. (Sumber: Laporan Keuangan Pemerintahan Kabupaten Hulu Sungai Utara 2015).

Sehingga dengan ini peran Retribusi Pajak Restoran cukup menarik untuk dibahas karena nilai yang dihasilkan tidak hanya sedikit untuk pertimbangan melakukan penarikan dengan benar dan tepat, akan tetapi isu dilapangan berbanding terbalik dengan hasil realisasi anggaran yang ada yaitu Dispenda mengaku masih kesulitan memungut pajak restoran karena kesadaran pengusaha restoran dan warung makan yang juga masih rendah. Potensi pendapatan dari pajak restoran, kata Galuh semestinya cukup besar mengingat pertumbuhan jumlah warung makan didaerahnya yang berkembang pesat dalam tiga tahun terakhir. Beberapa waralaba lokal Kalsel juga sudah bercokol di Bumi Kuripan tersebut. Tapi kenyataannya masih banyak pengusaha warung makan yang juga enggan membayar pajak atau hanya sedikit membayarkannya dari ketentuan perda.

Terlepas dari isu permasalahan diatas pada tahun 2012 Usaha Katering atau Produksi Makanan Rumahan memberikan sumbangsih kepada PAD Kabupaten Hulu Sungai Utara yang cukup besar Kepala Bidang Pendataan, Penelitian dan Penetapan pada Dinas Pendapatan Daerah Zulkifli Anwar Msi, mengatakan PAD dari hasil pungutan pajak restoran diatas 200 persen. Target PAD pajak katering $\mathrm{Rp}$. 25.000.000,- namun hingga Mei sudah mencapai Rp. 182.000.000,- atau sekitar 243 persen, pemasukan terbesar ungkapnya justru bukan berasal dari rumah makan besar atau restoran melainkan dari usaha jasa katering pada perkantoran pemerintah. Pengecualian juga diberlakukan bagi warung-warung tidak tetap seperti warung makan seafood yang saat ini hampir bisa ditemui dimana saja. Kepada warung makan jenis ini petugas hanya mengenakan karcis retribusi sebesar RP. 1000/hari mengingat pedagang sari laut yang buka hanya pada sore hari ini tidak memiliki lahan sendiri seingga tidak bisa dimasukan dalam objek pajak restoran yang tengah diberlakukan. (Sumber: antarakalsel.com Selasa, 10 Juli 2012 18.05 WIB)

\section{TINJAUAN PUSTAKA}

\section{Implementasi}

Studi implementasi merupakan suatu kajian mengenai studi kebijakan yang mengarah pada proses pelaksanaan dari suatu kebijakan. Implementaai kebijakan merupakan suatu proses yang begitu kompleks bahkan tidak jarang bermuatan politis dengan adanya intervensi berbagai kepentingan.

George Edward III sebagaimana dikutip oleh Leo Agustino (2012:149) dalam bukunya Dasar-dasar Kebijakan Publik menanamkan model implementasi kebijakan publik dengan Direct and Indirect Impact on Implementation. Dalam pendekatan yang dikemukakannya terdapat empat variabel yang sangat menentukan keberhasilan implementasi suatu kebijakan, yaitu:

1) Komunikasi

Menurut Edward III, komunikasi diartikan sebagai "proses penyampaian informasi komunikator kepada komunikan". Informasi mengenai kebijakan publik menurut Edward III perlu disampaikan kepada pelaku kebijakan agar para pelaku kebijakan dapat mengetahui apa yang harus mereka persiapkan dan lakukan untuk menjalankan kebijakan tersebut sehingga tujuan dan sasaran kebijakan dapat dicapai sesuai dengan yang diharapkan. Menurut Edward III, komunikasi kebijakan memiliki beberapa dimensi, antara lain dimensi transmisi (transmission), kejelasan (clarity), konsistensi (consistency).

2) Sumber Daya

Menurut Edward III mengemukakan bahwa faktor sumber daya mempunyai peranan penting dalam implementasi kebijakan. Menurut Edward III bahwa sumber daya tersebut meliputi sumber daya manusia, sumber daya anggaran, sumber daya peralatan, dan sumber daya kewenangan.

1) Sumber Daya Manusia

Merupakan salah satu variabel yang mempengaruhi keberhasilan pelaksanaan kebijakan. Menurut Edward III bahwa "probably the most essential resources in 
implementing policy is staff". Edward III menambahkan "no matter how clear and consistent implementation order are and no matter accurately theyare transmitted, if personnel responsible for carrying out policies lack th resource to do an effective job, will not effective".

2) Sumber Daya Anggaran

Menurut Edward III menyatakan dalam kesimpulan studinya "budgetary limitation, and citizen opposition limit the acquisition of adequate facilities. This is turn limit the quality of service that implementor can be provide to public". Menurut Edward III, terbatasnya anggaran yang tersedia menyebabkan kualitas pelayanan yang seharusnya diberikan kepada masyarakat juga terbatas.

Menurut Edward III menyatakan bahwa "new towns studies suggest that the limited supply of federal incentivies was a major contributor to the failure of the program". Menurut Edward III, terbatasnya insentif yang diberikan kepada implementor merupakan penyebab utama gagalnya pelaksanaan program. Menurut Edward III menyimpulkan bahwa terbatasnya sumber daya anggaran akan mempengaruhi keberhasilan pelaksanaan kebijakan. Disamping program tidak bisa dilaksanakan dengan optimal, kterbatasan anggarn menyebabkan disposisi para pelaku kebijakan rendah.

3) Sumber Daya Peralatan

Menurut Edward III menyatakan bahwa sumber daya peralatan merupakan sarana yang digunakan untuk operasionalisasi implementasi suatu kebijakan yang meliputi gedung, tanah, dan sarana yang semuanya akan memudahkan dalam memberikan pelayanan dalam implementasi kebijakan.

Menurut Edward III menyatakan: "Physical facilities may also be critical resources in implementation. An implementor may have sufficient staff, may understand what he supposed to do, may have authority to exercise his task, but without the necessary building, equipment, supplies and even green spase implementation will not succeed".

4) Sumber Daya Kewenangan

Sumber daya lain yang cukup penting dalam menentukan keberhasilan suatu implementasi kebijakan adalah kewenangan. Menurut Edward III menyatakan bahwa: "Kewenangan (authority) yang cukup untuk membuat keputusan sendiri yang dimiliki oleh suatu lembaga akan mempengaruhi lembaga itu dalam melaksanakan suatu kebijakan. Kewenangan ini menjadi penting ketika mereka dihadapkan suatu masalah dan mengharuskan untuk segera diselesaikan dengan suatu keputusan". Oleh karena itu, Edward III menyatakan bahwa pelaku utama kebijakan harus diberi wewenang yang cukup untuk membuat keputusan sendiri untuk melaksanakan kebijakan yang menjadi kewenangannya.

\section{Faktor-faktor Mempengaruhi Implementasi Kebijakan Publik}

Menurut Meter dan Horn (dalam Subarsono, 2005) terdapat enam variabel yang memberikan pengaruh terhadap implementasi kebijakan, yakni:

1. Standar dan sasaran kebijakan. Standar dan sasaran kebijakan menurut kedua pakar ini harus jelas dan terukur sehingga dapat direalisir. Apabila standar dan sasaran kebijakan kabur, maka akan terjadi multi interpretasi dan mudah menimbulkan konflik diantara agen pelaksanan.

2. Sumber daya, implementasi kebijakan memerlukan sumber daya baik sumber daya manusia (human resources) maupun sumber daya non manusia (non-human resources)

3. Hubungan antar organisasi. Dalam banyak program, implementasi sebuah program perlu dukungan dan koordinasi dengan instansi lain. Untuk itu, diperlukan koordinasi dan kerjasama dengan instansi lain agar sasaran kebijakan/program tercapai

4. Karakteristik agen pelaksana yang mencakup struktur birokrasi, norma-norma dan polapola hubungan yang terjadi dalam birokrasi, yang semuanya itu akan mempengaruhi 
implementasi dari suatu kebijakan

5. Kondisi sosial politik dan ekonomi yang mencakup sumberdaya ekonomi lingkungan implementasi kebijakan, sejauhmana kelompok-kelompok kepentingan memberikan dukungan bagi implementasi kebijakan, bagaimana sifat opini publik yang ada di lingkungan dan apakah elit politik mendukung implementasi kebijakan

6. Disposisi implementor yang mencakup tiga hal yang penting yaitu:

a) Respon implementor terhadap kebijakan yang akan mempengaruhi kemauan untuk melaksanakan kebijakan

b) Kognisi yaitu pemahamannya terhadap kebijakan

c) Intensitas disposisi implementor

\section{METODE PENELITIAN}

Pendekatan penelitian yang digunakan adalah pendekatan kualitatif yaitu proses penelitian yang menghasilkan data deskriptif, dengan menggunakan pendekatan ini karena memudahkan mengadakan penyesuaian dengan kenyataan, lebih mudah menyajikan secara langsung hakikat hubungan antara peneliti dan subjek penelitian.

Tipe yang digunakan dalam penelitian ini adalah tipe deskriptif, dimana penulis berupaya mendeskripsikan/ menggambarkan secara sistematis faktual dan akurat mengenai faktafakta, sifat-sifat serta hubungan antar fenomena yang ada.

Adapun Teknik Pengumpulan data dari Informan digunakan instrumen-instrumen penelitian yang disesuaikan dengan objek penelitian. Teknik pengumpulan data yang dilakukan dalam penelitian ini antara lain observasi, wawancara, dan dokumentasi.

\section{HASIL DAN PEMBAHASAN}

Implementasi Kebijakan Peraturan Daerah Nomor 15 Tahun 2011 Tentang Pajak Restorsan oleh Badan Pengelolaan Pajak dan Retribusi Daerah Kabupaten Hulu Sungai Utara.

Studi implementasi merupakan suatu kajian mengenai studi kebijakan yang mengarah pada proses pelaksanaan dari suatu kebijakan. Implementaai kebijakan merupakan suatu proses yang begitu kompleks bahkan tidak jarang bermuatan politis dengan adanya intervensi berbagai kepentingan. Implementasi adalah cukup untuk membuat sebuah program dan kebijakan yang kelihatannya bagus diatas kertas. Lebih sulit lagi merumuskannya dengan katakata dan slogan-slogan yang kedengarannya mengenakan bagi telinga para pemimpin dan para pemilih yang mendengarkannya. Dan lebih sulit lagi untuk melaksanakannya dalam bentuk cara memuaskan semua orang termasuk mereka dianggap klien.

1. Komunikasi

Secara garis besar tindakan yang dilakukamn oleh pihak instansi dalam menyelaraskan kejelasan perda tersebut dalam penerapan nya kepada rumah makan/restoran yang terkait sudah dengan berbagai cara akan tetapi masih adanya pihak rumah makan yang masih belum mengerti dan jelas akan implementasi perda tersebut.

2. Sumberdaya

Keadaan sumberdaya yang berperan dalam pelaksanaan implementasi ini sudah sangat mendukung dan memadai dari ketersediaan nya sumber daya manusia serta sarana dan prasarana yang mendukung lainnya jadi tinggal bagaimana prosedur pemanfaatan nya saja agar semua berjalan dengan lancar.

3. Disposisi

Dimana keadaan perilaku seorang pelaksana kebijakan dalam proses ini agen pelaksananya sudah sangat memadai akan tetapi masih ada beberapa yang belum berkompeten dibidang nya sehingga terdapat beberapa kendala seperti kurang tegas nya pihak penarik iuran pajak ini.

4. Struktur Birokrasi

Sasaran keberhasilan dalam pelaksanaan disini sangat tinggi sehigga terkadang pencapaian tidak mencukupi.

Faktor yang mempengaruhi Implementasi Kebijakan Peraturan Daerah Nomor 15 Tahun 2011 Tentang Pajak Restoran Oleh Dinas Pendapatan Daerah Kabupaten Hulu Sungai Utara. 
Adapun beberapa faktor yang menjadi hal berpengaruh dalam suatu kebijakan bisa jadi berupa suatu indikasi dalam penyebab kebijakan tersebut di berlakukan yang dapat memberikan penilaian apakah faktor tersebut pengaruh yang baik atau buruk dalam sistem penerapan kebijakan tersebut.

Dari berdasarkan hasil observasi serta wawancara yang dilakukan peneliti dalam lingkungan penerepan kebijakan perihal peraturan daerah nomor 15 tahun 2011 tentang pajak restoran yang dikelola oleh Badan Pengelolaan Pajak dan Retribusi Daerah sehingga tidak hanya dalam ruang lingkup kantor saja akan tetapi mengetahui bagaimana tanggapan serta timbal balik respon dalam penerapan kebijakan tersebut kepada pihak pengelola restoran/rumah makan yang berada dikawasan Kabupaten Hulu Sungai Utara.

Dari observasi serta menganilisis kembali permasalahan yang ada dalam hasil wawancara mengenai bagaimana implementasi perda tersebut oleh Badan Pengelolaan Pajak dan Retribusi Daerah sehingga dapat diketahui beberapa faktor yang mempengaruhi implementasi perda tersebut serta diperkuat dengan beberapa data dukung salah satunya hasil wawancara sebagai berikut. Sehingga diketahui beberapa faktor yang mempengaruhi yaitu

\section{Standar dan Sasaran Kebijakan}

Suatu standar keberhasilan dan sasaran dari kebijakan tersebut sudah direncanakan oleh pihak pemda yang berkoordinir langsung untuk membuat target pencapaian serta tingkat keberhasilan tiap kerja agar dapat diketahui seberapa besar presentasi keberhasilan pihak pengelola pajak dalam proses penerapan kebijakan peraturan daerah tersebut.

2. Karakteristik Agen Pelaksana

Dalam pelaksanaan penerapan kebijakan peraturan daerah mengenai pajak restoran ini dari segi karakteristik agen pelaksana nya sudah baik akan tetapi masih ada kekurangan nya dari segi bagaimana cara mereka mengatur waktu dalam proses penarikan retribusi tersebut agar semua pihak rumah makan tidak keberatan membayar yang dikarenakan belum laku nya rumah makan mereka.

3. Kondisi Sosial Politik dan Ekonomi

Bahwa keadaan sosial yang sering membiarkan untuk membuat kebiasaan menjadi sebuah tradisi yang dibenarkan sehingga memicu adanya kecurangan dalam pelaporan tiap hsil realisasi anggaran yang sudah di targetkan oleh pihak instansi. Serta adanya pehamanan mengenai keadaan ekonomi yang masih menjadi kesalah pahaman antara pihak rumah makan dengan pihak instansi bersangkutan sehingga tidak adnya kejelasan akan siapa yang berperan dan siapa yang diperankan.

\section{KESIMPULAN}

Berdasarkan penelitian yang penulis lakukan dengan mengacu pada beberapa tahapan dalam upaya untuk mengetahui bagaimana Implementasi Penerapan Kebijakan Peraturan Daerah Nomor 15 Tahun 2011 oleh Badan Pengelolaan Pajak dan Retribusi Daerah Kabupaten Hulu Sungai Utara, maka denagan ini didapat beberapa hasil yang dmuat dalam sebua kesimpulan guna mempermudah pembaca untuk mgengetahui intisari dari keseluruhan poin yang telah dijabarkan dan kemudian disimpulkan. Maka dengan ini berikut hasil penelitian yang telah disimpulkan :

1. Implementasi Kebijakan Peraturan Daerah Nomor 15 Tahun 2011 oleh Badan Pengelolaan Pajak dan Retribusi Daerah Kabupaten Hulu Sungai Utara, yang pada dasarnya telah dikelola dengan baik oleh pihak instansi yang bersangkutan dengan melakukan beberapa tahapan dari awal pemeberitahuan pemberlakuan perda sudah melakukan sosialisasi membujuk target sasaran pihak rumah makan untuk turut serta dalam penerapan dengan cara menghimbau secara langsung bagaimana proses penerapan. Baik dari pendaftaran/pelaporan omset, proses penarikan iuran, sampai pengelolaan nya. Tindakan yang dilakukan oleh instansi ini pun sudah cukup relevan dengan kondisi masyarakat di Kabupaten Hulu Sungai Utara tersebut, dimana masyarakatnya yang masih saja merasa 
adanya tradisi kekeluargaan dalam cara bertindak. Maka dengan ini pihak instansi masih memberikan adanya toleransi dalam tiap tindakan yang ada serta agar proses implementasi tersebut tetap berjalan kondusif meskipun target capaian keberhasilan implementasi nya cenderung lambat. Akan tetapi dengan adanya implementasi disini harus disertai dengan pihak lain dimana adanya proses timbal balik dalam mengelola jika ingin implementasi tetap berjalan dan mengalami peningkatan, maka harus adanya kesadaran dan peran serta dari masyarakat. Namun disini peran masyarakat masih kurang dalam proses pengelolaan implementasi tersebut karena disebabkan beberapa faktor dari segi pemahaman, kondisi sosial politik dan ekonomi masyarakat masih cenderung memiliki pola fikir yang belum terbuka dengan adanaya kemauan untuk bekerja sama dalam pembangunan daerah dengan ditangani langsung oleh masyarakat.

2. Faktor-faktor yang mempengaruhi dalam Implementasi Kebijakan Peraturan Daerah Nomor 15 Tahun 2011 oleh Badan Pengelolaan Pajak dan Retribusi Daerah Kabupaten Hulu Sungai Utara, memang tidak terlalu banyak namun disini sangat berperan penting dalam kelancaran dan keberhasilan implementasi tersebut dari hasil penelitian yang dilakukan ada 3 hal yang mempengaruhi proses implementasi tersebut. Standar dan sasaran kebijakan dimana standar yang diberlakukan tidak sejalan dengan proses yang diberlakukan dan juga sasaran pemberlakukan implementasi kebijakan tersebut yang masih belum aktual serta kurang adanya pemahaman yang jelas akan hal ini, karakteristik agen pelaksana yang masih belum menguasai bidang yang telah ditentukan serta kurang kompeten nya dalam bertugas, serta keadaan sosial politik dan ekonomi lokasi implementasi tersebut masih tidak terlalu memenuhi standar yang ditentukan dan kurang mendukung akan implementasi tersebut dengan tingkatan yang rendah.

\section{REFERENSI}

Abdul Wahab Solihin, 2016. Analisis Kebijakan Dari Formulasi ke Penyusunan Model-Model Implementasi Kebijakan Publik, Jakarta : PT. Bumi Aksara

Agustino Leo, 2008. DasarDasarKebijakanPublik, Bandung: ALFABETA,cv

Bungin Burhan, 2007. Penelitian Kualitatif, Jakarta: Prenada Media Group

Kansil, 1998. PengantarIlmuHukum Dan Tata Hukum Indonesia, Jakarta: BalaiPustaka

Kartiwa Asep, 2015. Metode Penelitian Administrasi. Bandung: CV. Pustaka Setia

Kuswana, Dadang. 2011. Metode Penelitian Sosial. Bandung: CV. Pustaka Setia.

Peraturan Daerah Nomor 15 Tahun 2011 tentang Pajak Restoran.

Riduan Akhmad, 2016. Hand-Out Mata KuliahKebijakanPublik

Santosa Pandji, 2012. Administrasi Publik Teori dan Aplikasi Good Governance, Bandung: PT. RefikaAditama

Subarso. 2005. Analisis Kebijakan Publik. Yogyakarta: Pustaka Pelajar.

Sudirman Rismawatti,Amirrudin Antong, 2015. Perpajakan Teori dan Praktik Indonesia. Jawa Timur: Empat Duamedia.

Sugiyono, 2014. Metode Penelitian Kuantitatif Kualitatif Kualitatif dan $R \& D$. Bandung: CV. Alfabeta

Winanrno Budi, 2014. Kebijakan Publik Teori, Proses, dan Studi Kasus. Jakarta: CAPS. 